\begin{abstract}
As you think about preparing for your future as a political scientist - are you considering studying or a career outside of the US? In this chapter, we draw on our collective experiences from Spain and the UK to sketch out some key issues you might want to consider when looking at graduate courses or academic positions abroad. Are there any major trade-offs that need to be considered? From master's level to doctoral studies through securing your first political science academic post, and everything in-between. We attempt to explore and unpack these to lay out the options available for prospective and current graduate students thinking about their future prospects as political science academics beyond the US.
\end{abstract}

This manuscript is part of Strategies for Navigating Graduate School and Beyond, a forthcoming volume for those interested in pursuing graduate education in political science (Fall 2022 publication).

\title{
Title
}

\section{Weighing Up the Options. Adventure of an Academic Career Outside of the US?}

\section{Authors}

Dale Mineshima-Lowe ${ }^{1}$, Pablo Biderbost ${ }^{2}$, and Guillermo Boscán Carrasquero ${ }^{3}$

\section{Introduction}

In considering one's prospects for a career in political science within and outside of the academy, there are good reasons for looking at wider options available in terms of programs beyond those within the USA. Previous studies have attempted to address the pedagogical as well as practical reasons for studying beyond one's "home" country and have focused on added value of intercultural exchanges to one's academic career (Asada 2019). Drawing on our collective experiences, we offer some insights about pursing academic opportunities outside the US.

Collectively, we have found our experiences of studying and working outside of the US have added a richness to our ways of learning, teaching and research that is difficult to quantify. The experiences have also opened avenues of opportunities we would not have considered otherwise, through the development of more global networks. The enrichment of studying abroad at the graduate level can have a far-reaching impact on one's outlook and prospects beyond immediate considerations (Paige et al 2009). This is something that is usually understated as it is more nebulous and doesn't demonstrate immediate impact. However, there are some key considerations and trade-offs, both short-term and long-term ones, to reflect upon before one takes the plunge. This chapter is by no means conclusive in its coverage, but more of an overview of key reflections with reference to our experiences from the United Kingdom (UK) and Spain to illustrate these insights.

\footnotetext{
${ }^{1}$ Associate Lecturer, Departments of Politics \& Geography, Birkbeck - University of London, UK

${ }^{2}$ Associate Professor of Political Science at the Universidad Pontificia Comillas, Spain.

${ }^{3}$ Assistant Professor of Political Science at the University of Salamanca, Spain.
} 


\section{Master's Level Studies Abroad}

There are several key considerations for looking at an academic career outside of the US, but a main one perhaps to reflect upon is, 'What do you hope to get out of the experience?' Other top questions to consider - How long do I want to be abroad? And what is the purpose of my studying? (e.g., Is it to develop specialist knowledge for use in my current job? Do I want to change directions in my career? Or am I thinking about pursuing a doctoral study in political science but am unsure of what this will entail?)

In terms of pursuing master's level studies in political science abroad - there are a wealth of reasons for studying abroad - international experiences, new contacts, different perspectives, regional / local specialisations, shorter time abroad, etc. However, perhaps if one is considering a master's program abroad, two key tips to consider are the duration and the focus of the programs you are shortlisting. For example, in the UK, while political science (referred to as 'politics') courses can differ, most generally run for twelve-months (full-time). The difference is that some are taught courses (so specific topic courses taken along with then completing an independent research dissertation over a three or four-month period). While others are researchonly courses (where you spend the entire time conducting fieldwork/research and writing to complete a dissertation). This distinction between 'taught' and research-focused master's courses are similar in Spain and with similar durations for the completion of studies. With taught versus research-focused programs, the route one selects is dependent on one's reasons (building specialist-topic knowledge and methodologies versus conducting detailed research and fieldwork), along with one's academic background at the undergraduate level, and any other work/life experiences.

In terms of the focus and types of programs available, for example in Spain there are master's level programs designed for different purposes. There are non-official master's degrees (or "Títulos Propios" in the Spanish academic jargon) that focuses more on development of skills and knowledge for the professional market and are generally connected to labor opportunities. Other master's degree programs considered 'official', have been developed to let those who obtain their diplomas enter doctoral studies. In comparison to Spain, most UK master's degrees in politics serve the dual purpose of providing pathways towards professional development for those already working in say policy making or business sectors, as well as a pathway for those who are interested in pursuing doctoral studies.

This understanding of how political science master's degree courses are designed and structured is important. In the Spanish and British examples, they demonstrate how the duration, structure and rationale for these courses are developed and the audiences they are seeking to serve. These are important points to note in programs one is looking at, as while the prestige of an institution can be very useful, decisions should also consider whether the program is a good match to what you want it for in terms of your own career path and progression. This is the case for graduate programs in any country, however, thinking ahead about opportunities specific programs have with other parts of the world can provide added value to a choice of program. A good example is the strong connection of graduate courses in Spain to universities and other organisations outside of academia in both the European Union and Latin or Ibero America. Additionally, while program-specific benefits may be clear in terms of the cultural and personal benefits, it is also useful to consider within the context of the 
wider university and community where you will be based during your studies and if it is a good 'match' to more personal needs and individual identities.

\section{A Political Science Career Outside of the US}

A second important question I was asked during my doctoral studies in the UK, which I totally valued at the time was, 'Where do you want to establish your academic career?' This is a great question in our view, as sometimes we are so focused on the political science program while we are 'doing', that we do not think to contemplate 'where do I want to be when this is done'. In addition, this reflection really links decisions about completing doctoral studies abroad and future career prospects. That said, there is nothing to say studying abroad negates taking up an academic post in the US or vice versa. Only that there are contacts and networks developed during doctoral studies that can help with finding and securing first academic posts (postdoctoral researcher or teaching ones).

While we were all discussing our experiences as doctoral students in Spain and the UK, some of the key tips we thought would be useful were focused on the duration, the quality and recognition of programs, added value of programs in each that perhaps were less known, costs and funding, but also personal considerations in terms of dependents and for those who identify as part of minoritized populations.

One of the contrasting points to consider between doctoral programs within the US and Spain or the UK for example, is the duration of programs on average. Doctoral studies in both Spain and the UK can be completed in three years (full-time) and five years (part-time). This differs vastly from the US, where many doctoral programs on average are undertaken in five years (full-time). We draw this point to start, as there are obvious balances to be had in terms of the duration of a program, entry into the academic career market, and financial costs associated with studying abroad based on the length of program and home/international fees to be paid and living costs.

As with any doctoral program, a key consideration is the quality of degree programs. While generally UK doctoral politics degrees are highly recognized, this recognition of quality is something that has also been increasing in recent years for programs in Spain. For both Spain and the UK, the quality of its political science programs has centered around the staff within universities based on their research and teaching competencies. In Spain for instance, professors must have a clear record of recent, quality publications and material resources must be provided to the students (such as access to books, software licences, or support for participating in international conferences or for publishing with high standards in competitive journals). Likewise in the UK, the participation of universities in both the Research Excellence Framework (REF) to assess the excellence of research undertaken by staff, as well as the Teaching Excellence Framework (TEF) to assess the quality of teaching ${ }^{4}$ should provide indications about the quality of programs and staff.

\footnotetext{
${ }^{4}$ Both measuring frameworks provide an evaluation of research and teaching undertaken at UK universities and in the case of the REF, this is used to inform the allocation of public funding for universities in research. The TEF is voluntary and publicly funded universities and colleges in receipt of a TEF award are allowed to charge tuition to a different level than non-TEF institutions.
} 
In today's competitive graduate market, not only where and what is studied but also how to finance it, are major considerations. One the key tips in terms of finding funding for doctoral studies abroad, in general, is to start the process early. Funding applications need time, consideration, and in many cases, referees, or nominations as part of the process. While in the US context there are many internal university grants and awards that one can apply for, this is less the case in the UK and Spain. Some institutions will have their own specific funding lines, but in general, these are limited to specific programs, research topics, or there are restrictions on the nationality of applicants. In both Spain and the UK, American students can also apply for grants and scholarships within the US that allow for their use to fund doctoral studies abroad. ${ }^{5}$ Additionally, one could apply and use the American federal student loan process and send those funds to the UK or Spain to cover course fees and living costs.

In additional to the above funding streams - there are opportunities for doctoral politics students to undertake part-time teaching - partly to fund one's studies, but also to gain valuable experience as part of one's academic training. Not dissimilar to some of the opportunities available within the US for doctoral students, in the UK for example, doctoral students can serve as tutors (small group seminar leaders), as a university exams invigilator, or as a parttime research assistant on projects led by a member of staff in one's department. However, the other additional tips to for working in the UK while studying include being clear about your student visa conditions, applying for and receiving a British national insurance number (like the US social security number used to track work and tax contributions), and considering the overall impact of working on one's ability to complete research and writing within the expected timeframe.

Another key point when starting one's academic career (vis-à-vis doctoral studies abroad) is to consider the support available for international students of diverse backgrounds, in terms of ethnicity, gender identification, sexual orientation, and family-dependents needs. These considerations are becoming more integrated with increased international student recruitment. In Spanish universities this is an important dimension to consider as diversity is a key criterion for universities looking to advance their rankings. Similarly in the UK where international students are a part of its politics departments as well as the universities, diversity and inclusion has become a part of the university landscape. In the UK, the Equality Act 2010 provides guidance for universities, staff and students about legal protections in place for those studying or working who share a protected characteristic ${ }^{6}$.

The 'value added' of undertaking studies abroad, as mentioned earlier, are the cultural exchanges, experiences and new networks one develops. Related this are the number of opportunities to participate in domestic (e.g., British or Spanish-based) political science networks. For example, within the UK, political science networks such as the Political Studies Association (PSA), University Association in Contemporary European Studies (UACES), and the British International Studies Association (BISA), all have dedicated graduate student networks connected to the main organisations' bodies, but run by graduate students to provide opportunities to network and develop one's academic skills beyond research and teaching (e.g.,

\footnotetext{
${ }^{5}$ Further details of sources of funding are listed in the reference section. Also check individual institutions (e.g., LSE - London School of Economics and Political Science in the UK) for details of individual institutional funding available.

${ }^{6}$ Protected characteristics under UK law - age, disability, gender reassignment, marriage and civil partnership, pregnancy and maternity, race, religion or belief, sex, sexual orientation.
} 
organizing conferences, workshops, delivering conference papers and collaborative publishing). Similarly in Spain, the connections between Spain universities and those in Latin America and across the European Union adds value to studying abroad as these guarantee strong networks for participating in exchange programs.

When considering a future career in academia outside of the US, the above-mentioned points and tips (e.g., intersectional considerations, legal protections, developing networks, work visas, etc.) are also relevant for securing one's first political science academic post. Something to note, many universities (for instance in Spain and the UK) are seeking to diversify and internationalize their programs (Ortega-Ruiz et al 2021), they are also seeking to be more inclusive and many are actively encouraging applications from candidates less represented populations (based on age, ethnicity/race, gender, sexual orientation, disability/ablism). This is supported through provisions by governments in both Spain and UK, to provide visas for non-citizen academics taking up full-time positions, as well as support for dependent families and partners accompanying them.

In electing to search for an academic position outside of the US, there are expectations of what a new academic brings in terms of teaching experience, curriculum development, research and publishing which are like those expected by political science departments in the US. For example, in the Spanish context there are three typical activities expected of academics: teaching (with a clear mandate of "teaching innovation"), research (with the obligation of publications mostly in English but also in Spanish), and management (such as to be the "Tutor" of a group of students, the "Director" of a bachelor's degree program, or "Coordinator" of internship programs). This is similar for those seeking positions in the UK universities.

Additionally, it is worth noting that external accreditation (by quality assurance agencies) for both research and teaching are becoming a part of the job-seeking process in many countries outside of the US. In Spain for instance, this external approval is required for career progression in the academic arena (e.g., there is no promotion without a previous accreditation). External accreditation is used to evaluate the quality of the research, with university teachers evaluated every six years on the quality of their publication profiles. Impact of one's publication-research profile is reviewed with the Journal Citation Reports (JCR), the SCImajo Journal Rank (SJR), or journals published in the Scientific Publishing Institute (SPI). Similarly in the UK, as mentioned previously, the REF is a review process of research and publications by academics. The REF assesses submissions based on three elements: quality of outputs (so similarly to use of the SJR), impact beyond academia, and on the research support environment of universities and their departments. This is used to determine a department's ranking against other similar universities in terms of research output and follows a seven-year cycle with the most recent REF review taking place earlier in 2021.

Along with the external accreditation of research and publications, many universities are also seeking candidates with a formal university teaching qualification. Within the UK, this is not yet mandatory in most universities prior to the start of a position, however, it is highly desirable of candidates seeking positions. In many instances, universities are requiring new staff members to acquire fellow status through the professional membership scheme promoting excellence in higher education run by Advance Higher Education (AdvHE). The alternative is 
the completion of a graduate certificate in higher education program during one's probationary period.

Lastly, an important part of the decision-making process of one's career prospects is to consider the earning capacity of political science positions in universities as compared to perhaps the private, governmental or NGO sectors. Within the UK, academics on average earn less than their US counterparts (Stevens 2020). This is similar in Spain, where average salaries for political science academic positions are less attractive in comparison to places like the US and UK. However, like the UK, Spain boasts a good system of social healthcare and education. An additional bonus for academics seeking positions in Spain is that the cost of living is less than both the UK and the US, so this can compensate for the salary levels particularly earlier in one's career.

\section{Conclusion}

There are some key take-aways to consider when looking at studying (master's level or doctoral) and searching for political science academic jobs abroad as mentioned in this chapter. The most important one to consider is 'Why?'. What is the purpose behind studying abroad and are you looking at it as a short-term experience or are you a bit more open to seeing where things lead? Leaving yourself time to reflect on these questions, as well as time for short-listing perhaps five programs you're most interested in, is key. Secondly, look at the duration of the program to complete on average, the costs, and the types of funding available (including American federal loans) to see what a best fit for you is. Do remember to consider the costs of living and not just the costs of studying alone, as unlike in the US prospectuses for political science graduate programs, not all universities provide clear ideas about the costs of living associated to where the university is located. And again, leave yourself time to do your research on grants and other "free" money that you may be able to access (e.g., home-state scholarships, grants for specific ethnic groups, grants for specific programs and/or research topics, etc.). The time these take to find and complete are usually under-estimated. Third, as we will assume quality of research and teaching will be a key consideration in selecting a program, the next key consideration focuses on the extra-curricular opportunities available that will add value to the experience of studying abroad. These could be through the graduate program itself (e.g., work experiences, fieldwork trips, research assistant work, government internships, etc.), staff members in the department, or affiliate organizations. All of these key take-aways relevant for studying abroad are also very relevant for those looking to start their political science academic career abroad. Lastly, a great tip is to find a mentor who shares your research interests, affiliations, and that you like, who will be able to provide feedback and advice as you prepare to search for that first full-time political science academic job. Good Luck!

\section{Resources of Interest:}

British International Studies Association (BISA) - UK - www.bisa.ac.uk

London School of Economics and Political Science (LSE), Fees and Funding. Scholarships, studentships, loans and tuition fees. United Kingdom.

Available: https://www.lse.ac.uk/study-at-lse/graduate/fees-and-funding [Accessed:

December 21, 2021] 
Office for Students (UK) (2020) Equality and diversity.

Available: https://www.officeforstudents.org.uk/about/equality-and-diversity/what-does-thelaw-say/ [Accessed: December 21, 2021]

Political Studies Association (PSA) - UK - www.psa.ac.uk

Postgraduate Funding (website listing)

Available: https://www.postgraduatefunding.com/search/results?los=1\&sids=63 [Accessed:

December 12, 2021]

Research Excellence Framework (REF) - United Kingdom

Available: https://www.ref.ac.uk/about/ [Accessed: December 21, 2021]

Teaching Excellence Framework (TEF) - United Kingdom

Available: https://www.gov.uk/government/publications/government-response-to-theindependent-review-of-tef [Accessed: December 21, 2021]

University Association of Contemporary European Studies (UACES) - UK - www.uaces.org

\section{References:}

Advance Higher Education (AdvHE). Available: https://www.advance-he.ac.uk/ [Accessed: December 21, 2021]

Equality Act 2010 - Technical Guidance on Further and Higher Education. Equality and Human Rights Commission.

Available: https://www.equalityhumanrights.com/sites/default/files/equalityact2010technicalguidance-feandhe-2015.pdf [Accessed: December 21, 2021]

Equality and Human Rights Commission (2019) The further and higher education institutions provisions of the Act

Available: https://www.equalityhumanrights.com/en/advice-and-guidance/further-andhigher-education-institutions-provisions-act [Accessed: December 21, 2021]

Ortega-Ruiz, Manuela, José Real-Dato, and Miguel Jerez Mir. 2021. "Late but Not Least? Spanish Political Science's Struggle for Internationalisation in the Twenty-First Century." European Political Science 20 (1): 159-82. https://doi.org/10.1057/s41304-021-00315-z.

Paige, R. Michael, Gerald W. Fry, Elizabeth M. Stallman, Jasmina Josić, and Jae-Eun Jon. 2009. "Study Abroad for Global Engagement: The Long-term Impact of Mobility Experiences." Intercultural Education 20 (sup1): S29-44. https://doi.org/10.1080/14675980903370847.

Stevens, Philip Andrew. 2004. "Academic Salaries in the UK and US." National Institute Economic Review 190 (October): 104-13. https://doi.org/10.1177/002795010419000110.

Wood, J. 2021. "What's the Teaching Excellence Framework (TEF)?", Complete University Guide. Available: https://www.thecompleteuniversityguide.co.uk/student-advice/where-tostudy/teaching-excellence-framework-tef [Accessed: December 21, 2021] 